\title{
Presentation and outcomes of indigenous Australians with peripheral artery disease
}

Tejas P. Singh ${ }^{1,2,3}$, Joseph V. Moxon ${ }^{1}$, Genevieve N. Healy ${ }^{3}, Y_{\text {vonne Cadet-James }}^{4}$ and Jonathan Golledge ${ }^{1,2^{*}}$ (D)

\begin{abstract}
Background: The risk factors for peripheral artery disease (PAD) are more common in Indigenous than nonIndigenous Australians, however the presentation and outcome of PAD in Indigenous Australians has not been previously investigated. The aim of this prospective cohort study was to compare the presenting characteristics and clinical outcome of Indigenous and non-Indigenous Australians with PAD.

Methods: PAD patients were prospectively recruited and followed-up since 2003 from an outpatient vascular clinic in Townsville, Australia. Presenting symptoms and risk factors in Indigenous and non-Indigenous patients were compared using Pearson's X2 test and Mann Whitney U test. Kaplan Meier survival analysis and Cox proportional hazard analysis were used to compare the incidence of myocardial infarction (MI), stroke or death (major cardiovascular events) among Indigenous and non-Indigenous patients.

Results: Four hundred and one PAD patients were recruited, of which 16 were Indigenous and 385 were nonIndigenous Australians. Indigenous Australians were younger at entry (median age 63.3 [54.7-67.8] vs 69.6 [63.3-75. $4]$ ), more commonly current smokers (56.3\% vs $31.4 \%$ ), and more frequently had insulin-treated diabetes (18.8\% vs 5.2\%). During a median follow-up of 2.5 years, five and 45 major cardiovascular events were recorded amongst Indigenous and non-Indigenous Australians, respectively. Indigenous Australians were at $\sim 5$-fold greater risk of major cardiovascular events (adjusted hazard ratio 4.72 [95\% confidence intervals 1.41-15.78], $p=0.012$ ) compared to non-Indigenous Australians.
\end{abstract}

Conclusions: These findings suggest that Indigenous Australians with PAD present at a younger age, have higher rates of smoking and insulin-treated diabetes, and poorer clinical outcomes compared to non-Indigenous Australians.

\section{Background}

Peripheral artery disease (PAD) refers to a range of stenosing and aneurysmal disorders of the extra-coronary and extra-cerebral arteries [1]. Examples of common PAD pathologies include lower limb occlusive disease, abdominal aortic aneurysm (AAA), and carotid artery stenosis. The burden of PAD is significant. Lower limb occlusive disease is estimated to affect $\sim 200$ million people worldwide, [2] and $\sim 20$ million people are estimated to have AAA [3]. Moreover, the prevalence of PAD is expected to double by 2040 due to population

\footnotetext{
* Correspondence: jonathan.golledge@jcu.edu.au

${ }^{1}$ Queensland Research Centre for Peripheral Vascular Disease, College of Medicine and Dentistry, James Cook University, Townsville, QLD 4811, Australia

${ }^{2}$ The Department of Vascular and Endovascular Surgery, The Townsville Hospital, Townsville, QLD, Australia

Full list of author information is available at the end of the article
}

aging [4]. Despite current best care, PAD patients are at approximately three times higher risk of cardiovascular and all-cause mortality, compared to those without PAD [5]. Mortality attributed to PAD has been estimated to be higher in Australasia than in any other part of the world (3.89 per 100, 000 [95\% CI 2.2-6.9]) [6]. The reasons for this have not been clearly demonstrated although one possible explanation is the high incidence and complication rates of PAD amongst sub-sets of the Australasian population. Indigenous Australians could contribute to such a high risk sub-set since they have previously been reported to have an excess of risk factors for PAD and its complications [7].

Indigenous Australians (Aboriginal and Torres Strait Islanders) have been reported to have a life expectancy of approximately 17 years less than non-Indigenous Australians, and a burden of disease 2.5 fold higher [8]. 
Non-communicable diseases represent $70 \%$ of the health gap, of which cardiovascular diseases are the leading contributor, followed by diabetes [9]. Despite awareness of the excess burden of cardiovascular diseases in Indigenous Australians, it has been difficult to establish health priorities and policy for many vascular conditions. A major reason for this is the lack of reliable clinical data, as currently most data available stems from administrative government data, which does not capture the complete spectrum of diseases and associated risk factors. This is particularly true for medical conditions which require specific investigation based diagnosis such as PAD.

Indigenous Australians have previously been reported to have a 3-fold higher risk of developing PAD (adjusted for age, diabetes duration, and smoking status) [10]. They also have more frequent risk factors for PAD compared to non-Indigenous Australians, including diabetes (5-10 fold higher), [11] hypertension (3-8 fold higher), [11] and smoking (5-fold higher) [7]. Moreover, it has been estimated that the risk of major amputations (below or above the knee) in 25-49 year olds is approximately 40-fold higher in Indigenous compared to nonIndigenous Australians, attributable to the earlier onset of underlying conditions such as diabetes $[7,12]$. There is, however, little understanding of the presenting characteristics and outcome of PAD in this population. Therefore, the aim of this prospective cohort study was to compare the presenting characteristics and the risk of major cardiovascular events (myocardial infarction [MI], stroke or death) in Indigenous and non-Indigenous Australians with PAD presenting to an outpatient clinic in Townsville, Queensland, Australia.

\section{Methods}

\section{Study design}

This was a prospective cohort study of PAD participants recruited from an outpatient clinic in Townsville Hospital (Ethics [HREC/13/QTHS/125; SSA/13/ QTHS/203; HREC/14/QTHS/203; H6028 \& H5537] $[13,14]$. A 5-member Indigenous reference committee was consulted for approval of the research. The recruitment period for this cohort was between May 2003 and February 2016. Patients who provided written informed consent and met the following eligibility criteria were included: diagnosis of PAD by a vascular specialist as previously described, [13] including any of the following presentations: intermittent claudication, critical limb ischemia, asymptomatic or symptomatic carotid stenosis, and aortic or peripheral aneurysms. Patients who identified themselves as Aboriginal and/or Torres Strait Islanders were considered Indigenous. Patients who did not identify as Indigenous were considered non-Indigenous.

\section{Measures}

Clinical characteristics collected for each participant included: presenting complaint, age, sex, diabetes, hypertension, smoking history, dyslipidaemia, renal function (estimated glomerular filtration rate [eGFR]), ischaemic heart disease (IHD), history of stroke, and current medications. Hypertension and diabetes were defined by history or treatment for these conditions. Cigarette smoking classification was based on smoking history, and defined as current smoker (smoked within the last month), previous smoker or never smoked. IHD was defined by a history of myocardial infarction, angina or coronary revascularization. Serum creatinine was measured using a spectrophotometry method in a pathology laboratory as previously described [1]. eGFR was calculated using the Chronic Kidney Disease Epidemiology Collaboration formula, as this has previously been shown to best predict complications [1]. Abdominal aortic aneurysm (AAA) was defined as an orthogonal infrarenal aortic diameter of at least $30 \mathrm{~mm}$ on ultrasound or computed tomography angiography [13, 14]. A significant carotid artery stenosis was defined as $\geq 50 \%$ using Australian Society for Ultrasound in Medicine criteria $[13,14]$. Current prescriptions for aspirin, other antiplatelet agents, warfarin, beta-blockers, calcium channel blockers, angiotensin pathway inhibitors, metformin, insulin, frusemide and statins were recorded. Follow-up data was retrieved from out-patient visits, hospital chart reviews, linked data and /or inpatient admissions as previously described $[13,14]$. The primary outcome was to evaluate the differences in the combined incidence of major cardiovascular events (MI, stroke or death) between Indigenous and non-Indigenous Australians with PAD. The diagnoses of MI and stroke were made by Royal Australasian College of Physicians accredited physician in accordance with international guidelines $[15,16]$. Death was defined to include deaths from all causes. Linked data were based on International Classification of Diseases (ICD)-10 coding for MI (I21.0-I22.9) and stroke (I60.0-I64.0). Patients were censored at the first major event, or at the date of last review or linked data request, if they did not experience an event.

\section{Sample size calculation}

The required sample size was estimated according to a planned Cox regression analysis, examining the association of Indigenous status with major cardiovascular events. On the basis of previous PAD studies conducted at The Townsville Hospital, the incidence of major cardiovascular events was estimated to be $30 \%$ over 3 years, [17] and the model was designed to include the following variables: age, sex, IHD, diabetes, hypertension, smoking and Indigenous status. It was therefore estimated that approximately 230 patients in total would be 
needed to be included in order to attain 10 outcome events per degree of freedom for each predictor variable to be included in the Cox regression analysis [18].

\section{Statistical analysis}

The presenting symptoms and risk factors were compared between Indigenous and non-Indigenous patients using Pearson's $x^{2}$ test and Mann Whitney $\mathrm{U}$ test. The combined incidence of MI, stroke or death in Indigenous and non-Indigenous groups was assessed with Kaplan-Meier analysis with differences compared using the log rank test. Multivariate Cox proportional hazards analyses were undertaken to assess the association between Indigenous status and cardiovascular events, adjusting for relevant confounding risk factors and medications (hypertension, current smoking, diabetes, IHD, age, critical limb ischemia, insulin, frusemide, angiotensin converting enzyme $[\mathrm{ACE}]$ inhibitor, anti-platelet or anticoagulant prescription) across 3 different models. The selection of variables to adjust for was based on those which have been established as risk factors for PAD outcome, or were found to be significantly different between Indigenous and non-Indigenous patients. No violations of the proportional hazards assumption were observed. All analyses were performed using STATA version 14.1 (StataCorp, College Station, Texas, USA), and SPSS version 20.0 (IBM SPSS Inc., Chicago, Illinois, USA).

\section{Results}

\section{Participant characteristics}

Four hundred and one patients with PAD were included, of which 16 (4.0\%) were Indigenous and 385 (96.0\%) were non-Indigenous Australians. Indigenous participants were younger at entry (median age $63.3[54.7-67.8]$ vs $69.6[63.3-75.4], p=0.005)$, were more likely to be current smokers $(56.3 \%$ vs $31.4 \%, p=0.041)$ and have insulin-treated diabetes (18.8\% vs $5.2 \%, p=0.022)$. Indigenous participants were also more likely to be prescribed frusemide for heart failure (Table 1). A lower proportion of Indigenous Australians were prescribed a statin, although this difference was not significant. There were no significant differences in presenting complaint at entry between Indigenous and nonIndigenous Australians (Table 2).

Table 1 Demographic and risk factors of included PAD patients

\begin{tabular}{|c|c|c|c|}
\hline Characteristics & Indigenous $(n=16)$ & Non-Indigenous $(n=385)$ & $p$-value \\
\hline Age (y) & $63.3(54.7-67.8)$ & $69.6(63.3-75.4)$ & 0.005 \\
\hline Sex (\% Males) & $10(62.5 \%)$ & $293(76.1 \%)$ & 0.215 \\
\hline Diabetes mellitus & $7(43.8 \%)$ & $103(26.8 \%)$ & 0.135 \\
\hline Smoker & & & 0.041 \\
\hline Never & $0(0 \%)$ & $82(21.3 \%)$ & \\
\hline Current & $9(56.3 \%)$ & $121(31.4 \%)$ & \\
\hline Previous & $7(43.8 \%)$ & $182(47.3 \%)$ & \\
\hline Hypertension & $15(93.8 \%)$ & $290(75.3 \%)$ & 0.091 \\
\hline $\mathrm{HD}$ & $10(62.5 \%)$ & $164(42.6 \%)$ & 0.116 \\
\hline Stroke & $1(6.3 \%)$ & $38(9.9 \%)$ & 0.632 \\
\hline $\mathrm{eGFR}\left(\mathrm{mL} / \mathrm{min} / 1.73 \mathrm{~m}^{2}\right)$ & $79.0(46.5-85.8)[2]^{a}$ & $78(60.0-91.0)[93]^{a}$ & 0.416 \\
\hline \multicolumn{4}{|l|}{ Medications } \\
\hline Aspirin & $11(68.88 \%)$ & $252(65.5 \%)$ & 0.786 \\
\hline Other antiplatelet & $3(18.8 \%)$ & $66(17.1 \%)$ & 0.867 \\
\hline Frusemide & $4(25.0 \%)$ & $28(7.3 \%)$ & 0.010 \\
\hline ACEI & $10(62.5 \%)$ & $152(39.5 \%)$ & 0.066 \\
\hline Beta-Blocker & $6(37.5 \%)$ & 115 (29.9\%) & 0.515 \\
\hline Calcium channel blocker & $3(18.8 \%)$ & 115 (29.9\%) & 0.339 \\
\hline Metformin & $4(25.0 \%)$ & $69(17.9 \%)$ & 0.472 \\
\hline Insulin & $3(18.8 \%)$ & $20(5.2 \%)$ & 0.022 \\
\hline Statin & $13(81.3 \%)$ & $273(70.9 \%)$ & 0.370 \\
\hline
\end{tabular}

IHD ischaemic heart disease, eGFR estimated glomerular filtration rate, $A C E I$ angiotensin converting enzyme inhibitor, $A R B$ angiotensin receptor blocker ${ }^{a}$ Represents the number of missing data-points. Continuous data are presented as median [interquartile range] and were compared using Mann-Whitney $U$ test. Nominal data are presented as number (\%) and were compared using Pearson's $\mathrm{X} 2$ test. $P$-values highlighted in bold indicate significant differences 
Table 2 Presenting complaint at entry for Indigenous and non-Indigenous patients

\begin{tabular}{lll}
\hline Characteristics & $\begin{array}{l}\text { Indigenous } \\
(\mathrm{n}=16)\end{array}$ & $\begin{array}{l}\text { Non-Indigenous } \\
(\mathrm{n}=385)\end{array}$ \\
\hline Presentation $^{\mathrm{a}}$ & & $126(32.7 \%)$ \\
$\quad$ Intermittent Claudication & $8(50.0 \%)$ & 0.385 \\
Critical Limb Ischemia & $2(12.5 \%)$ & $24(6.2 \%)$ \\
Abdominal Aortic or peripheral aneurysm & $3(18.8 \%)$ & $142(36.9 \%)$ \\
Asymptomatic carotid stenosis & $2(12.5 \%)$ & $46(11.9 \%)$ \\
Symptomatic carotid stenosis & $1(6.2 \%)$ & $47(12.2 \%)$
\end{tabular}

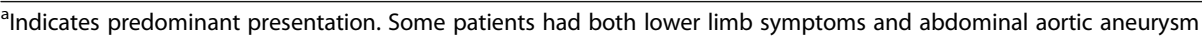

\section{Association between indigenous ethnicity and major cardiovascular events}

Median (inter-quartile range) follow-up in Indigenous patients and non-Indigenous patients was $2.5(0.3-5.3)$ and $2.5(0.4-5.4)$ years, respectively $(p=0.973)$. In total, five major cardiovascular events (MI, stroke, or death) were recorded in Indigenous Australians, and 45 major cardiovascular events were recorded in non-Indigenous Australians. Kaplan Meier curves illustrating the cumulative proportion of Indigenous and non-Indigenous patients who had major cardiovascular events are presented in Fig. 1. Differences between both groups were considered to be significant (log-rank test $p=0$.

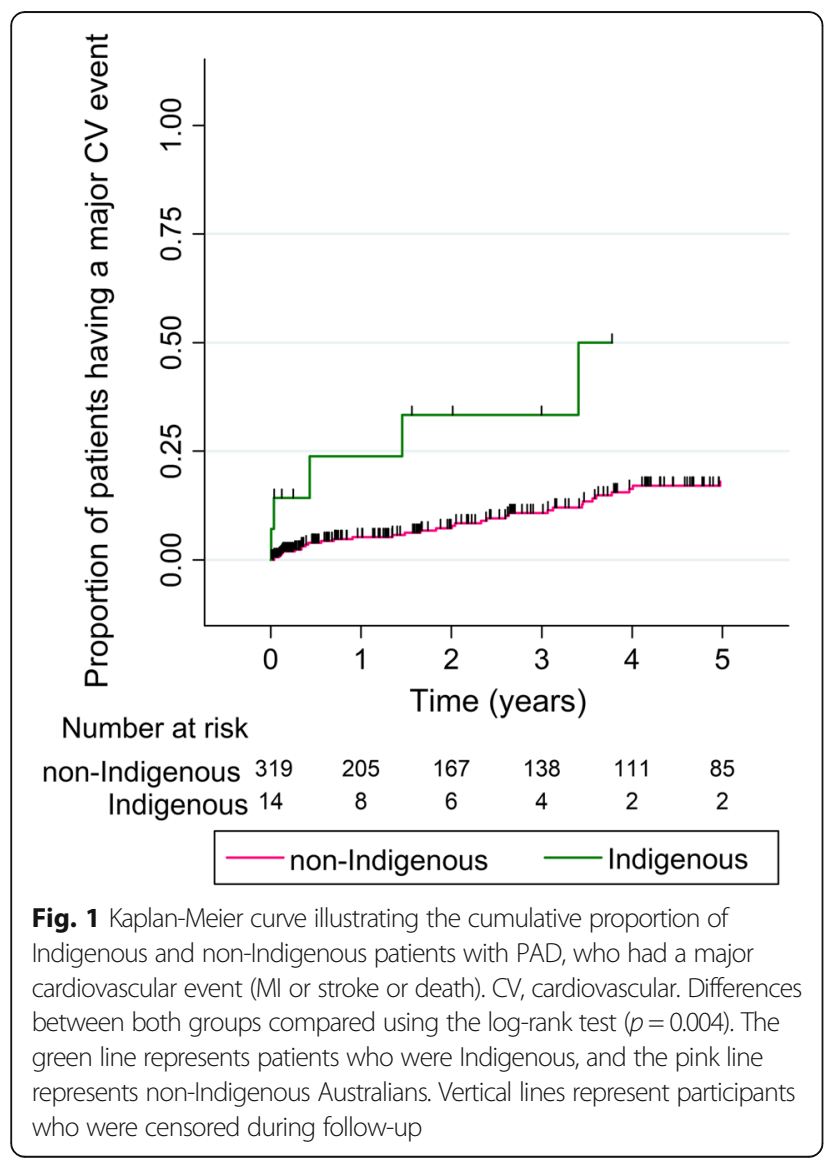

004). By unadjusted Cox proportional hazard analysis, Indigenous Australians had a 3.59-fold higher risk of major cardiovascular events during follow-up compared to non-Indigenous Australians ( $p=0.007$; Table 3$)$. By multivariate Cox proportional hazard analysis, Indigenous Australians were at $\sim 5$-fold greater risk of major cardiovascular events (HR 4.72 [1.41-15.78], $p=0.012$ ), after adjusting for hypertension, current smoking, diabetes, IHD, age, critical limb ischemia, insulin, frusemide, ACE inhibitor, anti-platelet or anti-coagulant prescription (Table 3).

\section{Discussion}

To our knowledge, this is the first comparison of the clinical presentation and outcome of PAD in Indigenous and non-Indigenous Australians. The results of this prospective cohort study suggest that Indigenous Australians present at a younger age with PAD, have more frequent cardiovascular risk factors, and are at significantly greater risk of developing major cardiovascular events compared to non-Indigenous Australians.

In this cohort, Indigenous Australians were more likely to have insulin-treated diabetes, which is reflective of the greater severity of diabetes in this population [7]. Indigenous Australians were more likely to be prescribed frusemide, which reflects the greater burden of heart failure in this population as previously identified [19]. In terms of outcome, Indigenous Australians were at approximately 5-fold greater risk of developing cardiovascular events in comparison to non-Indigenous Australians. Notably, these differences were seen despite the Indigenous cohort being, on average, younger than the nonIndigenous cohort which suggests early onset of PAD in this population. This may be due to earlier onset of PAD risk factors, such as diabetes, in Indigenous Australians [7]. It may also reflect greater prevalence of other risk factors for PAD in this population. Indigenous Australians had significantly higher smoking rates which is consistent with large observational studies [7]. Smoking is a strong risk factor for PAD, [20] and results from the Freemantle Diabetes Study 
Table 3 Cox proportional hazard analyses for the association between Indigenous ethnicity and combined incidence of major cardiovascular events (MI, stroke or death) in PAD patients

\begin{tabular}{lllll}
\hline & Unadjusted HR $(95 \% \mathrm{Cl})$ & Adjusted HR $(95 \% \mathrm{Cl})$ & $p$-value \\
\hline Ml, stroke or death & & & & \\
Non-Indigenous & 1.00 & - & 1.00 & - \\
Indigenous & $3.59(1.42-9.07)$ & 0.007 & $3.12(1.14-8.49)$ & $0.026^{\text {a }}$ \\
& - & - & $4.03(1.17-13.84)$ & $0.027^{\mathrm{b}}$ \\
& - & - & $4.72(1.41-15.78)$ & $0.012^{\mathrm{c}}$ \\
\hline
\end{tabular}

$\mathrm{MI}$ myocardial infarction, $\mathrm{Cl}$ confidence interval, $H R$ hazard ratio, IHD ischemic heart disease, $A C E$ angiotensin converting enzyme

${ }^{a}$ Results are adjusted for hypertension, current smoking, diabetes, IHD, and age

${ }^{\mathrm{b}}$ Results are adjusted for hypertension, current smoking, diabetes, IHD, age, insulin and frusemide prescription

'Results are adjusted for hypertension, current smoking, diabetes, IHD, age, insulin, frusemide, ACE inhibitor, anti-platelet or anti-coagulant prescription and critical limb ischemia

suggested that although smoking rates amongst nonIndigenous Australians has almost halved over the past 15 years, smoking rates have remained relatively unchanged in Indigenous Australians [7].

As with Australian data, previously published research in other countries focused on Indigenous populations has mainly looked at lower limb amputations secondary to diabetes-associated foot disease and cardiovascular events in patients that have diabetes [21-23]. It is therefore difficult to compare our findings to those reported regarding other Indigenous populations. In a retrospective analysis of Canadian Aboriginal and non-Aboriginal subjects with PAD, Aboriginal patients had a significantly higher prevalence of risk factors for PAD such as diabetes, hypertension, and renal failure, although Aboriginal ethnicity did not have an independent association with mortality [24]. A more comprehensive understanding of the epidemiology and outcome of PAD amongst different populations is warranted, given the high morbidity and mortality associated with this condition. In addition to differences in cardiovascular risk factors between Indigenous and non-Indigenous populations, previous studies have suggested that specific populations may have a predisposition to develop a particular anatomical distribution of arterial disease, which may contribute to poor clinical outcomes [25]. For example, in a retrospective analysis of 1215 PAD patients, the prevalence of aorto-iliac and infra-geniculate disease was higher in African-American and Asian populations compared to the Caucasian population [26-28]. In the current study, Indigenous Australians had more frequent lower limb presentations (intermittent claudication and critical limb ischemia) compared to non-Indigenous Australians, although differences were not significant. It is not yet clear whether these differences are related to ethnicity or rather clinical risk factors associated with distal PAD, such as diabetes [29].
This study has several limitations. Although our required sample size of 230 patients was exceeded, the recruited patients were unevenly distributed between the Indigenous and non-Indigenous groups (1:24). This is likely to have underpowered our study to detect significant differences in some established PAD risk factors and presenting complaints between Indigenous and non-Indigenous Australians. Although a significant association between Indigenous Australians with PAD and major cardiovascular events was established, confidence intervals were wide, which is reflective of the limited sample size, and it is possible that the true magnitude of the effect size may be different. Furthermore, data on important cardiovascular risk factors such as body mass index, glycaemic control, ankle brachial index and blood pressure were not collected. We only recruited participants from the outpatient setting, and were unable to include patients with emergency presentations, which may be of significance to Indigenous populations given greater rates and severity of diabetes and higher prevalence of complicating factors such as sepsis [30].

\section{Conclusion}

Placing our results in the context of what was previously known, this study highlights a significant health gap for Indigenous Australian patients with PAD. Indigenous Australians presented with PAD at a younger age, and were at significantly greater risk of major cardiovascular events compared to non-Indigenous Australians. They also more commonly had cardiovascular risk factors such as current smoking and insulin-treated diabetes, emphasising the need for more intensive management of modifiable risk factors in this population. Further study in this area with larger sample sizes is required to further characterise the excess burden of PAD in the Indigenous population, which may help identify additional clinical targets for improving PAD outcome. 


\section{Abbreviations}

AAA: Abdominal aortic aneurysm; ACE: Angiotensin converting enzyme; ARB: Angiotensin converting enzyme inhibitor; Cl: Confidence intervals; CV: cardiovascular; eGFR: Estimated glomerular filtration rate; HR: Hazard ratio; ICD: International Classification of Diseases; IHD: Ischaemic heart disease; MI: Myocardial infarction; PAD: Peripheral artery disease

\section{Acknowledgements}

Jonathan Golledge holds a Practitioner Fellowship from the National Health and Medical Research Council, Australia (1117061) and a Senior Clinical Research Fellowship from the Office of Health and Medical Research. Joseph $\checkmark$ Moxon holds an Advance Queensland Mid-Career Fellowship from the Queensland Government. Genevieve Healy is supported by a National Health and Medical Research Council Career Development Fellowship (108029). Tejas P Singh holds a Junior Doctor Research Fellowship from the Queensland Government.

\section{Funding}

This work was supported by a SERTA research grant from The Townsville Hospital (62701).

\section{Availability of data and materials}

The Queensland Research Centre for Peripheral Vascular Disease (QRCPVD) will oversee any materials sharing processes. Requests for data should be addressed to the corresponding author.

\section{Authors' contributions}

TPS composed the manuscript and conducted the statistical analyses. JG recruited patients, collected data, conceived the study and critically revised the manuscript. JVM contributed to study design, data analysis and interpretation and revision of the manuscript. GNH critically revised the manuscript. YCJ reviewed the manuscript and advised on Indigenous cultural aspects of the research. All authors read and approved the final manuscript. TPS, JVM and JG are guarantors for this work.

\section{Ethics approval and consent to participate}

This study has ethical clearance from The Townsville Hospital and Health Services Research Committee (HREC/13/QTHS/125; SSA/13/QTHS/203; HREC/14/QTHS/ 203; H6028 \& H5537). An especially formed 5-member Indigenous reference committee was consulted for approval of the research. All participates provided written informed consent

\section{Competing interests}

The authors declare that they have no competing interests.

\section{Publisher's Note}

Springer Nature remains neutral with regard to jurisdictional claims in published maps and institutional affiliations.

\section{Author details}

${ }^{1}$ Queensland Research Centre for Peripheral Vascular Disease, College of Medicine and Dentistry, James Cook University, Townsville, QLD 4811, Australia. ${ }^{2}$ The Department of Vascular and Endovascular Surgery, The Townsville Hospital, Townsville, QLD, Australia. ${ }^{3}$ The University of Queensland, School of Public Health, Herston, QLD, Australia. ${ }^{4}$ Indigenous Centre, James Cook University, Townsville, QLD, Australia.

Received: 7 February 2018 Accepted: 9 May 2018 Published online: 16 May 2018

\section{References}

1. Golledge J, Ewels C, Muller R, Walker PJ. Association of chronic kidney disease categories defined with different formulae with major adverse events in patients with peripheral vascular disease. Atherosclerosis. 2014; 232(N):289-297.

2. Fowkes FGR, Rudan D, Rudan I, Aboyans V, Denenberg JO, McDermott MM, et al. Comparison of global estimates of prevalence and risk factors for peripheral artery disease in 2000 and 2010: a systematic review and analysis. Lancet. 2013;382(9901):1329-40.
3. Sampson UK, Norman PE, Fowkes FGR, Aboyans V, Song Y, Harrell FE, et al Estimation of global and regional incidence and prevalence of abdominal aortic aneurysms 1990 to 2010. Glob Heart. 2014;9(1):159-70.

4. Criqui $\mathrm{MH}, \mathrm{Aboyans} \mathrm{V}$. Epidemiology of peripheral artery disease. Circ Res. 2015;116(9):1509-26.

5. Collaboration ABI. Ankle brachial index combined with Framingham risk score to predict cardiovascular events and mortality: a meta-analysis. JAMA. 2008;300(2):197.

6. UKA S, FGR F, MM MD, Criqui MH, Aboyans V, Norman PE, et al. Global and regional burden of death and disability from peripheral artery disease. Glob Heart. 2014;9(1):145-58.e21.

7. Davis TM, Hunt K, McAullay D, Chubb SA, Sillars BA, Bruce DG, et al. Continuing disparities in cardiovascular risk factors and complications between aboriginal and Anglo-Celt Australians with type 2 diabetes. Diabetes Care. 2012;35(10):2005-11.

8. Anderson IP. Closing the indigenous health gap. Aust Fam Physician. 2008; 37(12):982.

9. Vos T, Barker B, Begg S, Stanley L, Lopez AD. Burden of disease and injury in aboriginal and Torres Strait islander peoples: the indigenous health gap. Int J Epidemiol. 2009;38(2):470-7.

10. Maple-Brown L, Cunningham J, Dunne K, Whitbread C, Howard D, Weeramanthri T, et al. Complications of diabetes in urban indigenous Australians: the DRUID study. Diabetes Res Clin Pract. 2008;80(3):455-62.

11. Hoy WE, Kondalsamy-Chennakesavan S, Wang Z, Briganti E, Shaw J, Polkinghorne K, et al. Quantifying the excess risk for proteinuria, hypertension and diabetes in Australian aborigines: comparison of profiles in three remote communities in the northern territory with those in the AusDiab study. Aust N Z J Public Health. 2007;31(2):177-83.

12. Norman PE, Schoen DE, Gurr JM, Kolybaba ML. High rates of amputation among indigenous people in Western Australia. Med J Aust. 2010;192(7):421.

13. Golledge J, Cronin O, lyer V, Bradshaw B, Moxon JV, Cunningham MA. Body mass index is inversely associated with mortality in patients with peripheral vascular disease. Atherosclerosis. 2013;229(2):549-55.

14. Golledge J, Quigley F, Velu R, Walker PJ, Moxon JV. Association of impaired fasting glucose, diabetes and their management with the presentation and outcome of peripheral artery disease: a cohort study. Cardiovasc Diabetol. 2014;13(1):147.

15. Anderson JL, Adams CD, Antman EM, Bridges CR, Califf RM, Casey DE, et al. 2012 ACCF/AHA focused update incorporated into the ACCF/AHA 2007 guidelines for the management of patients with unstable angina/non-STelevation myocardial infarction. J Am Coll Cardiol. 2013;61(23):e179-347.

16. Wright L, Hill K, Bernhardt J, Lindley R, Ada L, Bajorek B, et al. Stroke management: updated recommendations for treatment along the care continuum. Intern Med J. 2012;42(5):562-9.

17. Cronin O, Bradshaw B, lyer V, Cunningham M, Buttner $\mathrm{P}$, Walker $\mathrm{PJ}$, et al. The association of visceral adiposity with cardiovascular events in patients with peripheral artery disease. PLoS One. 2013;8(12):e82350.

18. Peduzzi P, Concato J, Kemper E, Holford TR, Feinstein AR. A simulation study of the number of events per variable in logistic regression analysis. J Clin Epidemiol. 1996;49(12):1373-9.

19. McGrady M, Krum H, Carrington MJ, Stewart S, Zeitz C, Lee GA, et al. Heart failure, ventricular dysfunction and risk factor prevalence in Australian aboriginal peoples: the heart of the heart study. Heart. 2012;98(21):1562-7.

20. Golledge J. Lower-limb arterial disease. Lancet. 1997;350(9089):1459.

21. Young BA, Maynard C, Reiber G, Boyko EJ. Effects of ethnicity and nephropathy on lower-extremity amputation risk among diabetic veterans. Diabetes Care. 2003:26(2):495-501.

22. Simmons D, Scott D, Kenealy T, Scragg R. Foot care among diabetic patients in South Auckland. N Z Med J. 1995:108(996):106-8.

23. Lee ET, Russell D, Jorge N, Kenny S, Yu M-L. A follow-up study of diabetic Oklahoma Indians: mortality and causes of death. Diabetes Care. 1993;16(1): 300-5.

24. Goulet S, Trepman E, Mmath MC, Koulack J, Fong H, Duerksen F, et al. Revascularization for peripheral vascular disease in aboriginal and nonaboriginal patients. J Vasc Surg. 2006;43(4):735-41.

25. Bennett PC, Silverman S, Gill PS, Lip GYH. Ethnicity and peripheral artery disease. Int J Med. 2009;102(1):3-16.

26. Criqui $M H$, Vargas $V$, Denenberg JO, Ho E, Allison $M$, Langer $R D$, et al. Ethnicity and peripheral arterial disease. Circulation. 2005;112(17):2703-7.

27. Hobbs S, Wilmink A, Bradbury A. Ethnicity and peripheral arterial disease Eur J Vasc Endovasc Surg. 2003;25(6):505-12. 
28. Robbs J. Atherosclerotic peripheral arterial disease in blacks-an established problem. S Afr Med J. 1985;67(20):797-801.

29. Jude EB, Oyibo SO, Chalmers N, Boulton AJ. Peripheral arterial disease in diabetic and nondiabetic patients. Diabetes Care. 2001;24(8):1433-7.

30. O'rourke S, Steffen C, Raulli A, Tulip F. Diabetic major amputation in far North Queensland 1998-2008: what is the gap for indigenous patients? Aust J Rural Health. 2013;21(5):268-73.

Ready to submit your research? Choose BMC and benefit from:

- fast, convenient online submission

- thorough peer review by experienced researchers in your field

- rapid publication on acceptance

- support for research data, including large and complex data types

- gold Open Access which fosters wider collaboration and increased citations

- maximum visibility for your research: over $100 \mathrm{M}$ website views per year 